L. Masiero, R. Maggi

Estimation of indirect cost and evaluation of protective measures for infrastructure vulnerability : a case study on the transalpine transport corridor

Quaderno N. 10-03

Decanato della Facoltà di Scienze economiche

Via G. Buffi, $13 \mathrm{CH}-6900$ Lugano 


\title{
Estimation of indirect cost and evaluation of protective measures for infrastructure vulnerability: A case study on the transalpine transport corridor
}

\author{
Lorenzo Masiero \\ Rico Maggi \\ Istituto Ricerche Economiche (IRE) \\ Faculty of Economics \\ University of Lugano \\ Switzerland \\ Email: lorenzo.masiero@usi.ch, rico.maggi@usi.ch
}

September 162009

Version: 1.0

\begin{abstract}
Infrastructure vulnerability is a topic of rising interest in the scientific literature for both the general increase of unexpected events and the strategic importance of certain links. Protective investments are extremely costly and risks are distributed in space and time which poses important decision problems to the public sector decision makers.

In an economic prospective, the evaluation of infrastructure vulnerability is oriented on the estimation of direct and indirect costs of hazards. Although the estimation of direct costs is straightforward, the evaluation of indirect cost involves factors non-directly observable making the approximation a difficult issue. This paper provides an estimate of the indirect costs caused by a two weeks closure of the north-south Gotthard road corridor, one of the most important infrastructure links in Europe, and implements a cost-benefit analysis tool that allows the evaluation of measures ensuring a full protection along the corridor. The identification of the indirect cost relies on the generalized cost estimation, which parameters come from two stated preference experiments, the first based on actual condition whereas the second assumes a road closure. The procedure outlined in this paper proposes a methodology aimed to identify and quantify the economic vulnerability associated with a road transport infrastructure and, to evaluate the economic and social efficiency of a vulnerability reduction by the consideration of protective measures.
\end{abstract}

Keywords: infrastructure vulnerability, choice experiment, cost-benefit analysis, freight transport.

Acknowledgements: This paper is part of the NFP54 "Sustainable Development of the Built Environment" Project founded by the Swiss National Science Foundation. 


\section{Introduction}

Interruptions in infrastructure networks generate considerable economic and social damages at the regional and national level according to the overall dependency of the network on certain links and the risk associated with this interruption. In the context of increasingly vulnerable networks due to climate change, the attention on transport network reliability has grown substantially in the recent years in the international science community (Bell and Iida 2003, Nicholson and Dante 2004). Berdica (2002) introduces the road transport vulnerability as a complement of reliability, that is, the non-operability of a system due to incidents caused by either natural or man-made hazards.

Vulnerability assessment of a given transport infrastructure is mostly oriented on an engineering approach and regards the identification of the weakest points in a transportation network. Numerous methods have been proposed based on, for example, connectivity reliability (Bell and Ida, 1997), capacity reliability (Cheng et al., 2002) or accessibility index (Taylor et al., 2006).

In an economic prospective, the evaluation of infrastructure vulnerability is oriented on the estimation of direct and indirect costs of hazards. The former are associated with damages on the infrastructure caused by an unexpected event whereas the latter regard the consequences that the damaged infrastructure provokes on the society that depends on it. Although the estimation of direct costs is straightforward, the evaluation of indirect cost involves factors non-directly observable making the approximation a difficult issue. D'Este and Taylor (2003) proposed to calculate the loss of amenity of a link interruption as the change in generalized cost weighted by travel demand. Different algorithms have been proposed, as, for example, the short path algorithm. However, Taylor and D'Este (2004) recognized the limit in using algorithms as estimates of change in the utility of travel.

The estimation of the cost associated with an interruption of an infrastructure link is necessary in order to evaluate the desirability of any protective measure that allows a reduction of the vulnerability of the network to which it belongs. In this sense, a given vulnerability of a network represents a level of (expected) direct and indirect cost of a given hazard risk. Reducing vulnerability via costly protective measures can lead, as a function of the type of measure implemented, to an increased reliability (hazards have less or no consequences due to increased protection) or an increased resilience (networks recover faster from hazards). ${ }^{1} \mathrm{We}$ will concentrate here on the evaluation of protective measures creating "perfect" reliability (equivalent to a full insurance policy). This does not imply that we advocate zero vulnerability networks. Rather, a cost-benefit analysis of full protection measures on a given link will reveal whether this is economically justified and will in consequence contribute to move towards an economically optimal reliability. A methodology that allows the economic evaluation of the optimal reliability is still needed and required.

The aim of this paper is to estimate the indirect costs caused by a two weeks closure of an important trans-Alpine road corridor and to implement a cost-benefit analysis tool that allows the evaluation of measures ensuring a full protection along the corridor. We analysed one of the most important road infrastructure links in Europe, i.e. the north-south Gotthard road corridor. This corridor exhibits a high level of vulnerability because of its alpine geographical position and its long two-lane only tunnel (the third longest road tunnel in the world). The paper aspires to expand knowledge on how risk management has to be implemented to reduce potential damages and expected impacts and to improve the wider benefits due to enhanced network reliability.

\footnotetext{
${ }^{1}$ For a more detailed explanation of these concepts in a transport context see Husdal 2006)
} 
In order to reduce the complexity of the evaluation - evaluating the costs and benefits across the whole European road- and rail network would be an enormous task - the perspective has been reduced in several important ways. In a geographical sense we restrict the analysis to the Swiss Canton of Ticino, a part of the country south of the Alps and north of Italy, with two main trans-Alpine connections to the north - the Gotthard as a main connection and the San Bernardino a less important but still relevant link. Regarding cost we concentrate on indirect cost we limit our analysis to the sector that most depends on that road corridor, that is the Ticino freight transport market (inbound and outbound towards north). For this well delimited context we carried out two stated preference experiments addressed to logistic managers of 27 medium to large firms in Ticino. The first experiment involves choices in actual conditions whereas the second assumes a two week road closure.

Discrete choice model specification allows the generalized cost estimation through the derivation of the willingness to pay measures. Indeed, stated preference experiments are the most common techniques used in willingness to pay derivation and they allow to investigate the consumer behaviour in situations where few (or even none) data are available.

The cost benefit analysis is based on the change that an unexpected road interruption caused in the freight transport generalized cost. The evaluation of the economic sustainability of the risks identified along the corridor is then carried out by comparing the increase in the generalized cost with the cost of the protective measures. Finally, a cost benefit analysis tool is provided as a valid support of policy decision makers.

The paper is organized as follows. In section two we provide a brief geographical description of the infrastructure and we introduce the data. In section three we outline the discrete choice theoretical formulation. We present and discuss the model results in section four. The cost benefit analysis is performed in section five along with the introduction of the tool. Finally, conclusion and suggestion for further research are given in section six.

\section{Data}

The study concerns a choice based experiment, analysing the economic impact of a hypothetical closure of the Gotthard corridor ${ }^{2}$. Consequently we investigated the possible adaptive behavioural patterns of different actors in the face of disastrous and/or risky events. The investigation is based on the method of stated preferences. We basically want to model by means of an experimental design how the different actors react to the closure of this important road link across the Alps.

\subsection{Geographical context}

Due to its strategic position the corridor is one of the most important links between the north and the south of Europe. It represents a very important element of the national and international road and rail network facilitating transport and economic interaction between the north and the south of Europe.

Today, roughly $200 \mathrm{~km}$ of the Swiss national highway network are exposed to natural hazards, or in other words, every ninth kilometres leads through hazardous areas and hence

\footnotetext{
${ }^{2}$ The experiment began with some pilot interviews during February 2008, officially started in March 2008 and was finally concluded in June 2008.
} 
needs protection. A total of 137 galleries protect the traffic, more than 90 of them are rock fall protection measures. Additionally there are constructive measures directly in the hazard zones, such as protection nets, anchors, etc. The maintenance of these protection measures costs 30 Mio CHF every year ${ }^{3}$.

Between 1994 and 2004 freight transport by road and rail across the Alps grew by 68\% (rail traffic plus $25 \%$, road traffic plus $60 \%$ ). Today, the Alps are crossed each year by about 10 million trucks, a third of which passes through Switzerland, $85 \%$ of these using the Gotthard route $^{4}$.

\subsection{Stated preferences experiment}

We introduced the experiment by conducting an interview with the logistics managers of the most concerned industries (manufacturing) asking them about their general logistics and transportation framework and typical transportation relations across the $\mathrm{Alps}^{5}$. These managers were then confronted with alternative transportation services described by the use of three attributes, respectively, cost, time and punctuality. Cost and time attributes are pivoted to the reference values according to the levels shown in Table 1, whereas punctuality is expressed in absolute values.

Table 1. Attributes and their levels.

\begin{tabular}{ccc}
\hline Transport Cost & Transport time & Transport Punctuality \\
\hline$-10 \%$ & $-10 \%$ & $100 \%$ \\
$-5 \%$ & $-5 \%$ & $98 \%$ \\
Equal to the reference cost & Equal to the reference time & $96 \%$ \\
$+5 \%$ & $+5 \%$ & \\
$+10 \%$ & $+10 \%$ & \\
\hline
\end{tabular}

The whole experiment was based on a Computer Assisted Personal Interview (CAPI) instrument that randomly generates different profiles according to the assumption of experiment orthogonality. To each respondent 15 choice situations were presented.

The experiments refer to two different scenarios getting two different datasets. Examples of choice cards that the logistic manager was confronted with are given in Figures 2 and 3. In the first scenario we want to model behaviour with respect to the risk of frequent but short closures experienced currently along the road corridor, whereas in the second scenario we make the hypothesis of a rare incident provoking a two-week closure of the A2 highway. The first experiment analyzes the strategic decision on whether to stick to the currently chosen alternative (A2) given a known risk, or switch to a different one. In this sense we consider it to be a long-run choice among three different alternatives, namely, road (A2), piggyback and combined transport under the actual possibility of finding the A2 closed on a specific day. The road (A2) alternative remains fixed during the whole experiment since it describes the reference alternative. Its characteristics are those described by logistic managers for the typical transportation service across the Alps.

\footnotetext{
3 "La A2 a Gurtnellen un anno dopo la frana". Comunicato Stampa, Ufficio federale delle strade USTRA.

4 MONITRAF, Synthesebericht, Monitraf Aktivitäten und Ergebnisse, Endbericht, febbraio 2008, Innsbruck/Zürich.

${ }^{5}$ The decision to concentrate on the freight transport sector stems from past studies demonstrating that the passenger sector (tourism and business travel) exhibit almost negligible additional costs in the sequel of past closures. In particular, we refer to the closure of two months occurred in November 2001 following a frontal truck crash inside the $17 \mathrm{~km}$ long tunnel.
} 
Figure 1. Example of choice card for long-run decision experiment (first scenario) Suppose a situation where the road Gotthard corridor is going to be closed for a maximum of two consecutive days every month. Which of the following alternatives would you prefer?

\begin{tabular}{ccc}
\hline Road (A2) & Combined Transport & Piggyback \\
Actual cost & $5 \%$ more than & $5 \%$ less than \\
Actual time & actual cost & actual cost \\
Actual punctuality & $10 \%$ more than & $5 \%$ more than \\
actual travel time & actual travel time \\
\hline 0 & $100 \%$ punctuality & $96 \%$ punctuality \\
\hline
\end{tabular}

The second experiment regards a short-run decision since we make the hypothesis of a twoweek road closure - a rare event calling for a short term reaction. This choice situation is characterized by four alternatives, namely, road (A13), new road (regulated A13), piggyback and combined transport. In this second experiment the reference alternative is represented by the road (A13) alternative (that is the San Bernardino corridor) since it is the immediate rerouting alternative chosen by most road users when the Gotthard road corridor is closed.

In order to quantify the cost and time for the reference alternative (San Bernardino) we used the additional cost and the additional time with respect to Gotthard corridor resulting from a previous survey with six of the most important Ticino. There, all interviewed shippers replied with very similar additional cost and time, respectively $300 \mathrm{CHF}$ and 5 hours more for a detour via the San Bernardino route rather than along the Gotthard corridor. We get the values for the road (A13) alternative by summing these additional cost and time to the original reference values. Regarding the punctuality we assume a decrease of $2 \%$ with respect to the original value, with a minimum level fixed to the lowest level considered, that is, $96 \%$ of transports being punctual. This statement has been confirmed by the shippers interviewed, in particular if we consider the high volume of flows that occurs in a similar situation. To be noted that the validity of the transitional values is restricted to the closure period, that is fourteen days. The new road (regulated A13) alternative has been introduced to simulate a congestion free San Bernardino alternative (assume a sort of priority policy for trucks) with the original punctuality maintained.

Figure 2. Example of choice card for short-run decision experiment (second scenario)

Suppose a situation where the road Gotthard corridor is closed for two weeks.

Which of the following alternatives would you prefer?

\begin{tabular}{|c|c|c|c|}
\hline Road (A13) & Piggyback & Combined Transport & $\begin{array}{c}\text { New Road } \\
\text { (regulated A13) }\end{array}$ \\
\hline $\begin{array}{c}\text { Transitional } \\
\text { cost }\end{array}$ & $\begin{array}{l}10 \% \text { less than } \\
\text { transitional cost }\end{array}$ & $\begin{array}{l}5 \% \text { less than } \\
\text { transitional cost }\end{array}$ & $\begin{array}{l}10 \% \text { more than } \\
\text { transitional cost }\end{array}$ \\
\hline $\begin{array}{l}\text { Transitional } \\
\text { travel time }\end{array}$ & $\begin{array}{l}10 \% \text { more than } \\
\text { transitional travel time }\end{array}$ & $\begin{array}{l}5 \% \text { more than } \\
\text { transitional travel time }\end{array}$ & $\begin{array}{l}\text { Equal to } \\
\text { transitional travel time }\end{array}$ \\
\hline $\begin{array}{l}\text { Transitional } \\
\text { punctuality }\end{array}$ & $98 \%$ punctuality & $96 \%$ punctuality & $100 \%$ punctuality \\
\hline 0 & 0 & 0 & 0 \\
\hline
\end{tabular}

The sample is composed by 27 firms active in the manufacturing sector and, as mentioned before, all of them based in Ticino. The typical transport service described by logistic 
managers is reported in Table 2 . As expected, cost and time vary substantially since they are characterized by the distance between origin and destination and by the weight of the shipment, whereas punctuality is very homogenous and apart from two cases stating a $90 \%$ of punctuality in the transportation services all others are between 95 and 100 percent. This is in line with previous studies (see, for example, Bolis and Maggi 2003 and Maggi and Rudel 2008) and confirms the high level of importance that a logistics manager puts on a quality attribute like punctuality.

The descriptives for the damage and loss variables report a very low occurrence, with a sample mean of $0.97 \%$ and a median of $0.4 \%$. The damage and loss attribute is widely used but a matter of debate in literature because of its inconsistency and its frequent insignificance in the model estimation. In fact, it is meaningless to have a systematic damage or loss in the transport service because shippers/forwarders will self insure via a systematic solution, for instance a different packaging, or a different truck, or even a different mode of transport. Indeed, accidental damages might be happening but remain an occasional feature and not a characteristic of a transport service. For this reason, we chose to not include this attribute in our experiment. The descriptive statistics collected during the analysis confirm this decision.

Table 2. Sample descriptive statistics of typical transport service

\begin{tabular}{lrrrrr}
\hline Variable & Mean & Median & Std.Dev. & Minimum & Maximum \\
\hline Cost (CHF) & 1300.15 & 1000 & 1152.95 & 136 & 5400 \\
Time (hr) & 33.35 & 24 & 27.30 & 2 & 96 \\
Punctuality (\%) & 96.52 & 98 & 3.04 & 90 & 100 \\
Weight (ton) & 7.1309 & 5.50 & 7.17 & 0.04 & 25 \\
Distance O-D (km) & 474.33 & 300 & 332.62 & 92 & 1360 \\
MADD & 2.29 & 2 & 0.97 & 1 & 5 \\
Damage (\%) & 0.97 & 0.4 & 1.98 & 0 & 10 \\
Value (CHF/kg) & 203.28 & 40 & 487.38 & 0.36 & 2400 \\
\hline
\end{tabular}

Finally, from revealed market shares obtained for the whole logistic in the entire sample results, as expected, that the majority of the transport services rely on road alternative while the rest uses combined transport, either via rail or via ship and air. The piggyback alternative is not relevant confirming the weakness characterizing it due to technical problems and high operational cost.

\section{Theoretical background}

In a stated choice experiment, the respondent $n$ is supposed to select the alternative $j$ that maximizes his utility,

$$
U_{n j}=\boldsymbol{\beta}^{\prime} \mathbf{x}_{n j}+\boldsymbol{\varepsilon}_{n j}
$$

where $V_{n j}=\boldsymbol{\beta}^{\prime} \mathbf{x}_{n j}$ is the systematic part of the utility and $\boldsymbol{\varepsilon}_{n j}$ is the random term that is Independent and Identically Distributed (IID) extreme value type 1 . The estimation of the beta coefficients relies on the class of Random Utility Models (McFadden, 1974).

An advanced and widely used discrete choice model is the Random Parameter Logit (RPL) model, which allows for taste heterogeneity among respondents by letting the beta parameters 
randomly vary across the sample population (see Hensher and Green, 2003 for a detailed discussion). The following equation describes the choice probability for a RPL model:

$$
P_{n j}=\int_{\beta}\left(\frac{\exp \left(\boldsymbol{\beta}^{\prime}{ }_{n} \mathbf{X}_{n i}\right)}{\sum_{j} \exp \left(\boldsymbol{\beta}^{\prime}{ }_{n} \mathbf{X}_{n j}\right)}\right) f(\boldsymbol{\beta}) d(\boldsymbol{\beta})
$$

where parameters $\beta$ are drawn by continuous distributions (e.g. normal, log-normal, triangular etc.). The selection of a specific distribution, whenever possible, is based on previous knowledge or on particular behavioural assumptions. However, if no particular hypotheses are available or required, the selection is arbitrary and generally based on the goodness of fit of the data.

In a context of stated choice with repeated choice situations, an additional and indispensable feature of RPL models is the capability to deal with the panel structure by constraining the random parameters to be constant over choice situations. The choice probability in Equation (2) becomes then:

$$
P_{n j}=\int_{\beta}\left(\prod_{t} \frac{\exp \left(\boldsymbol{\beta}^{\prime}{ }_{n} \mathbf{X}_{n i t}\right)}{\sum_{j} \exp \left(\boldsymbol{\beta}^{\prime}{ }_{n \mathbf{X}}{ }_{n j t}\right)}\right) f(\boldsymbol{\beta}) d(\boldsymbol{\beta})
$$

where $\mathrm{t}=1, \ldots, \mathrm{T}$ indicates the number of choice situations. Since in any RPL model the choice probability integral has no closed form solutions, the estimation process is based on simulations and the log-likelihood takes the following form:

$$
L L_{n}=\sum_{n} \ln \frac{1}{R} \sum_{r} \prod_{t} \frac{\exp \left(\boldsymbol{\beta}_{n}^{\prime} \mathbf{x}_{n i t}\right)}{\sum_{j} \exp \left(\boldsymbol{\beta}^{\prime}{ }_{n} \mathbf{X}_{n j t}\right)}
$$

where, $\mathrm{r}=1, \ldots, \mathrm{R}$ indicates the simulation draw. The following models are based on 200 Halton draws ${ }^{6}$.

\section{Model estimation results}

Different Panel RPL models were estimated ${ }^{7}$ for the two scenarios and the selection was based according to both model fit indicators and behavioural meaning. Specifically, the evaluation of the model goodness of fit is provided by the final log-likelihood as well as the McFadden pseudo $\rho^{2}$ and the Akaike's Information Criterion (AIC).

The estimation of the utility functions for the first scenario is based on the following panel RPL specification:

\footnotetext{
${ }^{6}$ See Train (2003) for details.

${ }^{7}$ Models estimation is performed by Nlogit 4 .
} 


$$
\left\{\begin{array}{l}
V_{n(\mathrm{~PB})}=A S C_{\mathrm{PB}}+\beta_{(P B)} \mathrm{C} \mathrm{C}_{\mathrm{PB}}+\beta_{(P B)} \mathrm{T} \mathrm{T}_{\mathrm{PB}}+\beta_{\mathrm{P}} \mathrm{P}_{\mathrm{PB}} \\
V_{n(\mathrm{CT})}=A S C_{\mathrm{CT}}+\beta_{(C T) \mathrm{C}} \mathrm{C}_{\mathrm{CT}}+\beta_{(C T) \mathrm{T}} \mathrm{T}_{\mathrm{CT}}+\beta_{\mathrm{P}} \mathrm{P}_{\mathrm{CT}} \\
V_{n(\mathrm{RD})}=\beta_{(R D) \mathrm{C}} \mathrm{C}_{\mathrm{RD}}+\beta_{(R D) \mathrm{T}} \mathrm{T}_{\mathrm{RD}}+\beta_{\mathrm{P}} \mathrm{P}_{\mathrm{RD}}+\beta_{n \mathrm{D}} \mathrm{D}+\beta_{n} \mathrm{~W} \mathrm{~W}
\end{array}\right.
$$

where $A S C_{(j)}$ refers to the alternative specific constant, $\beta_{(j) C}, \beta_{(j) T}$ and $\beta_{P}$ are the coefficients associated to cost, time and punctuality while $\beta_{n D}$ and $\beta_{n W}$ are the parameters of the firm's logistics specific variables referring to transport service origin-destination distance (in kilometres) and shipment weight (in tonnes). Coefficients $\beta_{n D}$ and $\beta_{n W}$ are selected to be triangular distributed ${ }^{8}$ whereas all the other coefficients are supposed to be invariant over the sample, that is, the entire information is supposed to be captured by the sample mean.

The estimation results for the first scenario are shown in Table 3. The road (A2) alternative has been set as the reference alternative, and then the signs of the alternative specific constants indicate a slight preference for the road alternative even if the t-ratio test does not confirm their statistical significance. The alternative specific coefficients associated to cost and time attributes are all significant at an alpha level of 0.01 ( 0.05 for road time coefficient) and present the expected negative sign. The generic parameter for punctuality is also strongly significant and positive, reflecting an increase in utility in correspondence of an increase in transport service punctuality.

Table 3. Panel RPL estimate for the first scenario

\begin{tabular}{lrr}
\hline \multicolumn{3}{c}{ Means for Random and Non-Random parameters } \\
\hline Piggyback Constant & -0.98342 & $(-0.69)$ \\
Combined Transport Constant & -1.29087 & $(-0.91)$ \\
Piggyback Cost & -0.00554 & $(-5.92)$ \\
Combined Transport Cost & -0.00539 & $(-5.79)$ \\
Road (A2) Cost & -0.00624 & $(-4.55)$ \\
Piggyback Time & -0.10645 & $(-3.48)$ \\
Combined Transport Time & -0.09660 & $(-3.22)$ \\
Road (A2) Time & -0.10668 & $(-2.44)$ \\
Punctuality & 0.37771 & $(6.62)$ \\
Distance O-D & 0.00315 & $(1.29)$ \\
Weight & 0.06435 & $(0.60)$ \\
\hline \multicolumn{1}{c}{ Standard deviations for Random parameters } \\
\hline Ts Distance O-D & 0.02570 & $(3.20)$ \\
Ts Weight & 0.36608 & $(2.22)$ \\
\hline Sample & \multicolumn{3}{c}{405} \\
Final Log-l & \multicolumn{2}{c}{0.338} \\
McFadden pseudo $\rho^{2}$ & & 1.519 \\
AIC & &
\end{tabular}

The coefficients associated with the two firm specific variables show a mean not statistically different from zero, however they capture a significant heterogeneity among respondents, indicating that part of the respondents prefer to switch to rail-based alternatives as either the transport distance or the shipment weight increases.

\footnotetext{
${ }^{8}$ The selection of the triangular distribution was based on model fit preference. See Hensher and Green (2003) for discussion about triangular distribution use in discrete choice modelling.
} 
The analysis of the first scenario continues with the estimation of the monetary values of the quality attributes (time and punctuality) defined as the ratio of the marginal utility of the quality attribute to the marginal utility of the cost attribute. Within discrete choice class of models the derivation is straightforward since the parameter estimates refer to the marginal utility. In this context, we indicate the value of time (VOT) as $\beta_{j C} / \beta_{j T}$ and the willingness to pay for punctuality (WTPP) as $\beta_{P} / \beta_{j C}$.

In Table 4 we report the monetary measures (per shipment and per tonne) of time and punctuality obtained for the three transport alternatives presented in the first scenario. The road alternative shows a value of time (17.1 CHF/hour) similar to previous studies (Bolis and Maggi, 2003, Maggi and Rudel 2008, Zamparini and Reggiani 2007). The VOT for the two rail-based alternatives result in a higher value compared to the road alternative, namely 17.9 and 19.2 for piggyback and combined transport, respectively. This is in contradiction with Zamparini and Reggiani (2007) who analyse the value of time reported in published studies in the period 1990-2005 and observe a VOT higher for road than for rail freight transport. However, it should be noted that among the 46 studies analysed by Zamparini and Reggiani (2007) only 5 contained rail values, , 4 of which were conducted in the period 1990-1992 and one in 2000 .

The willingness to pay for an increase of $1 \%$ in punctuality goes from $60.5 \mathrm{CHF}$ for road alternative to $70.1 \mathrm{CHF}$ for combined transport. These values confirm recent studies regarding the high importance of punctuality as a transport service quality (see for example, Danielis et al., 2005, Fowkes et al. 2004).

Table 4. WTP measures and generalized cost for the first scenario

\begin{tabular}{lcccccc}
\hline & VOT & VOT/ton* & WTPP & WTPP/ton* & Market Share & Generalized Cost \\
\hline Piggyback & 19.21 & 2.63 & 68.15 & 9.34 & 24 & 1901 \\
Combined & 17.93 & 2.46 & 70.13 & 9.61 & 33 & 2183 \\
Road (via A13) & 17.09 & 2.34 & 60.50 & 8.29 & 43 & 1886 \\
\hline * Average tons loaded (from sample average) $=7.3$ & \\
\hline
\end{tabular}

The estimation of the model parameters and the derivation of the monetary values of quality changes makes the computation of the generalized cost straightforward. In fact, according to Hensher and Button (2000), the generalized cost is a linear combination of cost and any variable that is likely to impact on a given transport service. In our case, we assume that transport cost, time and punctuality have an impact on logistics manager's choice. The generalized cost associated to each alternative is then given by the following equation:

$$
G C_{j}=C_{j}+V O T_{j} \times T_{j}+W T P P_{j} \times\left(100-P_{j}\right)
$$

where $C_{j}, T_{j}$ and $P_{j}$ are the alternative specific variables cost, time and punctuality. In Table 4 we report the average generalized cost for each alternative alongside the proportion in percentage points indicating the share of the preferences among the alternatives (market share).

The results indicate a consistent proportion of the logistics managers $(24 \%)$ willing to switch mode of transport from road to piggyback under the hypothetical market condition assumed by the experiment design, that is, a piggyback mode transport really thought as a concrete and efficient alternative to the road. 
The combined transport shows the highest generalized cost and confirms the market share registered in the actual market. As expected, the freight transport via road reports the lowest generalized cost and it still is the most preferred alternative even if the logistics manager is well-aware of the chances that frequent road closures might cause a delay to his transport. This result could be explained in several ways, from risk propensity to mode switch inelasticity. However, a more realistic explanation is that, as reported by the majority of the respondents, the rail-based alternatives are not sufficiently competitive in the given logistics context (high frequency low weight shipments, relatively short distance covered across the Alps within Switzerland) to allow a risk reduction by switching the transport mode from road to rail-based alternatives. This holds in spite of important policy efforts (heavy subsidies, open access of freight operators on rail) to shift freight traffic from road to rail, and a high frequency of short closures in winter (mostly due to the heavy snowfall) and in summer (caused by the long queues at the tunnel bottleneck leading to a postponing of departure).

According to the objective of quantifying the economic vulnerability of the road infrastructure under an unexpected and long closure, we set the average generalized cost of a freight transport via road, $1886 \mathrm{CHF}$, as the starting point of the cost-benefit analysis 9 .

In order to obtain the monetary values for time and punctuality associated with an unexpected total closure of the road Gotthard corridor for two consecutive weeks, we introduce the logistics managers to the second scenario. The specification of the panel RPL model is given by:

$$
\left\{\begin{array}{l}
V_{n(T r N R)}=A S C_{T r \mathrm{NR}}+\beta_{(T r N R)} \mathrm{C} \mathrm{C}_{T r \mathrm{NR}}+\beta_{(T r N R)} \mathrm{T}_{T r \mathrm{NR}}+\beta_{T r} \mathrm{P} \mathrm{P}_{T r \mathrm{NR}} \\
V_{n(T r \mathrm{~PB})}=A S C_{T r \mathrm{~PB}}+\beta_{(T r P B)} \mathrm{C} \mathrm{C}_{T r \mathrm{~PB}}+\beta_{(T r P B)} \mathrm{T} \mathrm{T}_{T r} \mathrm{~PB}+\beta_{T r} \mathrm{P} \mathrm{P}_{T r \mathrm{~PB}} \\
V_{n(T r \mathrm{CT})}=A S C_{T r \mathrm{CT}}+\beta_{(T r C T) \mathrm{C}} \mathrm{C}_{T r \mathrm{CT}}+\beta_{(T r C T) \mathrm{T}} \mathrm{T}_{T r \mathrm{CT}}+\beta_{T r \mathrm{P}} \mathrm{P}_{T r \mathrm{CT}} \\
V_{n(T r \mathrm{RD})}=\beta_{(T r R D)} \mathrm{C} \mathrm{C}_{T r \mathrm{RD}}+\beta_{(T r R D)} \mathrm{T} \mathrm{T}_{T r \mathrm{RD}}+\beta_{T r} \mathrm{P} \mathrm{P}_{T r \mathrm{RD}}+\beta_{M D} \mathrm{MD}+\beta_{n} \mathrm{D} \mathrm{D}+\beta_{n} \mathrm{~W} \mathrm{~W}
\end{array}\right.
$$

where the two rail-based alternatives share now the choice set with two road alternatives, road via A13 (TrRD) and new road (TrNR). The suffix "Tr" indicates that the attributes (as well as the coefficients and the utility functions) refer to the transitional detour values. We also introduce a further logistics characteristic of the firm, called maximum acceptable delivery delay (MADD), which is a 5 point discrete variable and expresses the delay tolerance allowed by the client, during an unexpected event, without any additional charge to be paid by the supplier.

The logistics managers were then faced with the updated reference alternative profile, and they were reminded that these new conditions hold just for two transitional and consecutive weeks. The results for this second scenario are shown in Table 5.

The sign and the magnitude of the alternative specific constants indicate the new road (regulated A13) alternative as the most preferred since it presents the highest ASC value. Nevertheless, the two rail-based alternatives, namely, piggyback and combined transport, are also preferred to the actual road alternative (A13). The cost and time alternative specific

\footnotetext{
${ }^{9}$ In order to verify that our insistence on the frequent risk of short closures had not influenced the respondents' parameters we also have derived the generalized cost by using a dataset collected among Swiss firms aimed to evaluate the quality attributes in freight transport (described in Rudel and Maggi, 2008). Even running different specification models the resulting generalized cost was very similar to the one obtained with this first scenario.
} 
coefficients are highly significant (at an alpha level of 0.01 ) and with the expected sign as well as the generic punctuality parameter.

Table 5. Panel RPL estimate for the second scenario

\begin{tabular}{lrr}
\hline & Coefficient & (t-ratio) \\
\hline \multicolumn{2}{c}{ Means for Random and Non-Random parameters } \\
\hline New Road Constant & 3.81419 & $(1.98)$ \\
Piggyback Constant & 3.31834 & $(1.72)$ \\
Combined Transport Constant & 3.03794 & $(1.58)$ \\
New Road Cost & -0.00576 & $(-8.60)$ \\
Piggyback Cost & -0.00568 & $(-8.47)$ \\
Combined Transport Cost & -0.00562 & $(-8.35)$ \\
Road (via A13) Cost & -0.00719 & $(-6.53)$ \\
New Road Time & -0.13314 & $(-5.79)$ \\
Piggyback Time & -0.13192 & $(-5.61)$ \\
Combined Transport Time & -0.12924 & $(-5.41)$ \\
Road (via A13) Time & -0.11486 & $(-3.59)$ \\
Punctuality & 0.38859 & $(9.10)$ \\
MADD & 1.64419 & $(2.36)$ \\
Distance O-D & -0.00041 & $(-0.12)$ \\
Weight & 0.01737 & $(0.13)$ \\
\hline \multicolumn{1}{c}{ Standard deviations for Random parameters } \\
\hline Ts Distance O-D & 0.00983 & $(2.87)$ \\
Ts Weight & 0.37209 & $(2.06)$ \\
\hline Sample & & 405 \\
Final Log-1 & & -387.22 \\
McFadden pseudo $\rho^{2}$ & & 0.509 \\
AIC & & \\
\hline & & \\
\hline
\end{tabular}

The parameter associated with the logistics firm specific "MADD" variable is significant and positive, showing the logistics manager's aversion to look for better temporary alternatives as the flexibility in the delivery delay increases. As for the first scenario, the origin-destination distance and the transport weight variables result with mean values of zero but with significant standard deviation helping to capture the heterogeneity across respondents.

From the coefficient estimates we derive the monetary values for time and punctuality associated with each of the four alternatives considered in the second scenario. The VOT and WTPP values, calculated as the ratio of the quality attribute coefficient to the cost coefficient, are shown in Table 6. Compared to the first scenario, the two rail-based alternatives experience a significant VOT increase whereas the WTPP values do not show consistent differences. Similar VOT and WTPP values are identified for the new road alternative. On the contrary, the VOT and WTPP for freight transport on the San Bernardino road corridor (A13) are valued less than those for the Gotthard road corridor (A12) reflecting the well known problems that trucks face along the former corridor (i.e. steep road with low average curve radius). Thus, apart from the road (A13) alternative, the results obtained for the monetary values highlight that in a short term emergency condition the logistics managers increase their perception of time without altering their perception of punctuality. This confirms, as previously stated, the high importance of the transport punctuality that is at its maximum all year long. 
Table 6. WTP measures and generalized cost for the second scenario

\begin{tabular}{lcccccc}
\hline & VOT & VOT/ton* & WTPP & WTPP/ton* & Market share & Generalized Cost \\
\hline New Road & 23.13 & 3.17 & 67.52 & 9.25 & 32 & 2455 \\
Piggyback & 23.22 & 3.18 & 68.40 & 9.37 & 28 & 2523 \\
Combined & 23.01 & 3.15 & 69.17 & 9.48 & 27 & 2602 \\
Road (A13) & 15.98 & 2.19 & 54.07 & 7.41 & 13 & 2304 \\
\hline
\end{tabular}

Finally, the average generalized cost for each transport mode alternative has been computed according to the following equation:

$$
\operatorname{Tr}\left(G C_{j}\right)=\operatorname{Tr}\left(C_{j}\right)+\operatorname{Tr}\left(V O T_{j}\right) \times \operatorname{Tr}\left(T_{j}\right)+\operatorname{Tr}\left(W T P P_{j}\right) \times\left[100-\operatorname{Tr}\left(P_{j}\right)\right]
$$

where $\operatorname{Tr}\left(G C_{j}\right)$ are the alternative specific generalized costs during the two-week closure period, $\operatorname{Tr}\left(V O T_{j}\right)$ and $\operatorname{Tr}\left(W T P P_{j}\right)$ refer to the monetary measures estimated from the second scenario and $\operatorname{Tr}\left(X_{j}\right)$ are the typical transport cost, time and punctuality variables updated to the new values according to the emergency situation. The results are given in Table 6 together with the second scenario market shares. The reference alternative (A13) shows both the lowest generalized cost and the lowest market share because of the low punctuality set for this alternative. However, the transport by road is still the most preferred since the regulated road alternative (an "uncongested" A13) shows the highest market share and a lower generalized cost than the two rail-based alternatives.

In general, the additional generalized cost estimated is approximately $600 \mathrm{CHF}$ per transport. In particular, the value of travel time saving increases consistently while the willingness to pay for 1 percent more of punctuality is more stable.

\section{Cost-Benefit Analysis tool}

The construction of this module relies on the results of both stated choice experiments described in the previous sections. In particular, the module is built in order to estimate the indirect user cost of a two week closure of the road Gotthard corridor ${ }^{10}$. The results obtained from the first scenario provide the starting value for the generalized cost in an everyday condition while the results obtained from the second scenario are used in the estimation of the additional generalized cost. Figure 3 shows how the main worksheet appears to the user. A detailed help page is also provided by clicking the apposite button.

The structure of the module is organized in six sections:

1. Scenario setting: shows the alternatives and the attributes used in the estimation modelling. Zero correspond to the default values, by inputting different values (either positive or negative) we generate a scenario;

2. Closure details: allows different closure period settings and changes in traffic flow and reference generalized cost;

\footnotetext{
${ }^{10}$ The tool is available upon request from the corresponding author.
} 
3. Market shares: shows the market shares in percentage and in number ${ }^{11}$ for both default and scenario values;

4. Generalized cost: shows the additional generalized cost ${ }^{12}$ caused by a two-week closure of the road corridor for the Ticino economy;

5. Cost-benefit analysis for critical points in the Gotthard corridor: allows the computation of the net present values of the selected measures aimed to reduce the whole vulnerability of the road Gotthard corridor;

6. Net present values chart: highlights in a histogram chart the net present values of the selected measures distinguishing between default and scenario values.

In the Ticino freight transport market, the estimated indirect cost caused by an unexpected two-weeks closure of the road Gotthard corridor is 4.63 Mio CHF (see Figure 3). Therefore, any infrastructure investment aimed at reducing the probability of a two-week closure should be compared with a saved cost of 4.63 Mio CHF.

Figure 3. Estimation page and example of scenario analysis for long closure

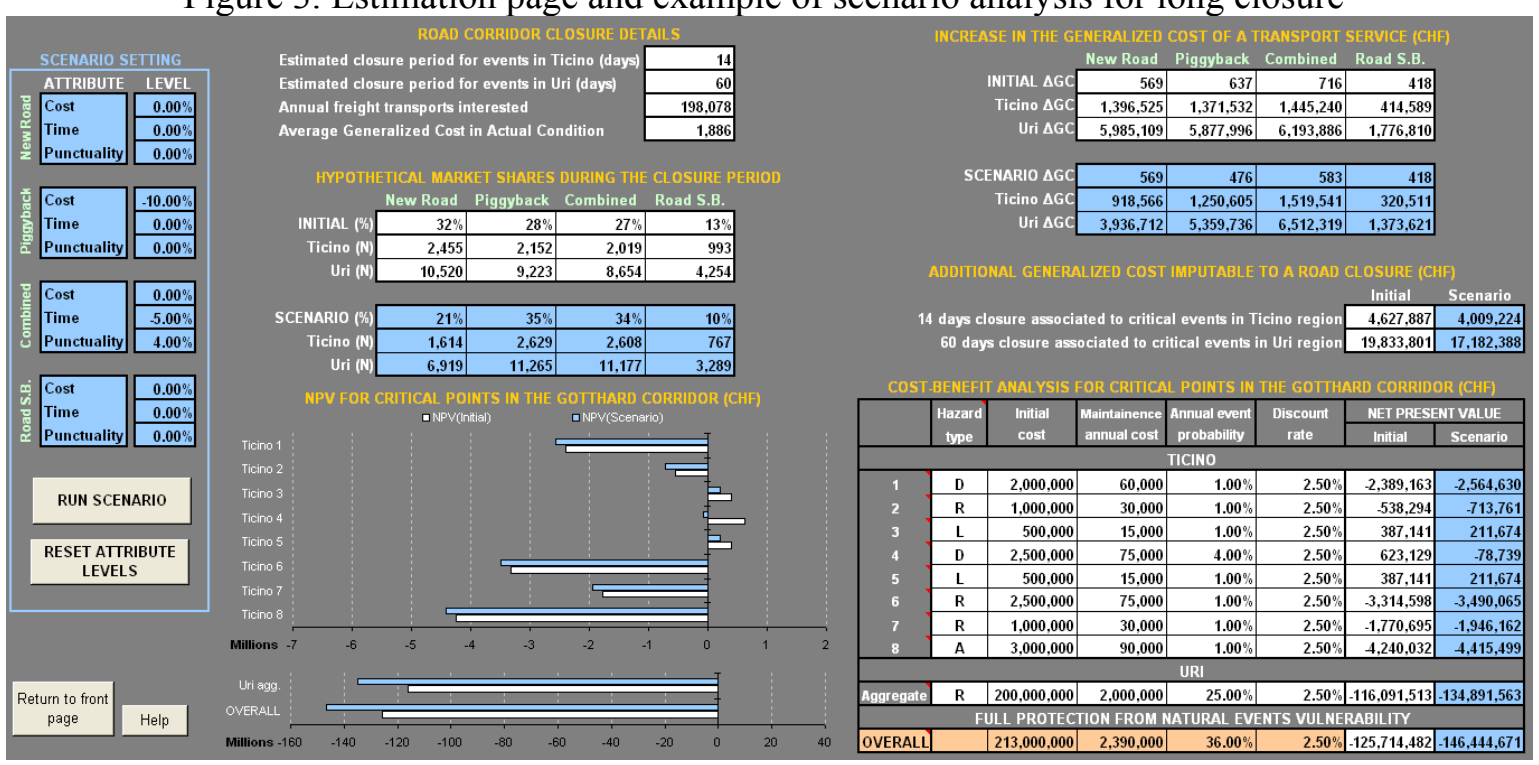

Regarding the cost-benefit analysis section we illustrate nine critical points along the whole corridor, eight of which are those identified in Ticino (south of the Alps) with the geoscientific risk analysis ${ }^{13}$ and one is an assumed hazard in the Canton of Uri (north of the Alps). For each of them a mitigation measure can be defined establishing zero hazards at this point. In other words, the protection of the link against an unexpected long closure is complete regarding this location. The user has to input the initial cost, the annual maintenance cost of the selected measure, the risk of closure according to the annual event probability and the appropriated discount rate. Then, the tool provides the net present value (NPV) for each one of the measures considering a project lifetime of 50 years. Calculating a separate NPV for each mitigation measure implies that we simulate a situation where the whole benefit (savings

\footnotetext{
${ }^{11}$ The source of the total amount of trucks passing through the Gotthard corridor is the last AQGV 04 census. We consider only trucks departing from or arriving to Ticino. This amount is inputted in the cell called $\mathrm{N}$ and it is free to be changed by the user.

${ }^{12}$ The reference value is put into the cell GC_Gotthard and stems from the first scenario results.

${ }^{13}$ The critical points and the protective measures are reported in Appendix, Table A1. We thank Mirko Baruffini for providing with the information.
} 
in generalised cost) is attributed to a single measure but weighted by the probability of the hazard.

Assuming a low discount rate of 0.025 and a realistically low event probability of 0.01 , measures 3 and 5 against landslides and measure 4 against debris flow result in a positive NPVs. Together they would reduce the risk of closure by $6 \%$. The other measures show negative NPV. This implies that large investments, like e.g. the hypothetical one in URI, or smaller ones in Ticino but for low event probability are not justified if we consider only the indirect benefit for Ticino. Expanding the analysis and adding the direct benefits and above all indirect benefits for the rest of Switzerland, and Europe (transit traffic accounts for 50\% of the trans-Alpine passages) might change the results significantly in favour of the measures.

By changing the infrastructure parameters the user can explore alternative policy measures that might lead to different vulnerability outcomes changing the economic efficiency of a given protective measure. For example, by assuming a ten percent cost reduction for the piggyback alternative and, a five percent time reduction and a four percent punctuality increase for the combined transport alternative, the cost of a two-week road closure would be 4 Mio CHF (see Figure 3), that is, 13.4 percent less than the actual estimated loss. This makes the net present value of protective measure 4 not positive anymore.

Finally, the versatility of the module allows the integration of any further information gathered about the exact number of sensible points located along the Gotthard road corridor and the exact monetary value of each measure aimed at mitigating the risk of a long closure.

\section{Conclusion}

This paper has investigated the economic consequences associated with a two-week closure of the Gotthard road corridor, and has analysed the economic efficiency of different protective measures through the implementation of a cost-benefit analysis.

Due to its geographical location and to the seventeen kilometres long two-lane tunnel, the Gotthard corridor experiences a high degree of vulnerability towards unexpected events. In fact, in recent years two disastrous events occurred. In November 2001, a head-on collision between two trucks inside the tunnel caused a two months road interruption while, in May 2006, a rock fall caused a closure of one month.

We provide the indirect cost in the economic sector that most heavily depends on the road corridor, that is, the Ticino freight transport market. The identification of the indirect cost relies on the generalized cost estimation, which parameters come from two stated preference experiments, the first based on actual condition whereas the second assumes a road closure.

The results indicate that a two-week closure of the Gotthard road corridor generates an indirect user cost to the Canton Ticino of 4.63 Mio CHF. As a consequence, the cost of any measure avoiding this risk has to be compared with the potential benefit of saving at least this sum (if benefits to other regions and direct benefits are neglected). In this context, nine critical points along the corridor were identified and the cost-benefit analysis indicates a positive net value for three protective measures resulting in a reduction of the road closure risk of six percent. 
The implementation of the cost-benefit tool is essential in testing different scenarios useful in the evaluation of different policy setting. In fact, the tool lets the service transport parameters, cost, time and punctuality, free to change. For example, an improvement of the rail-based alternatives in term of cost, time and punctuality can reduce significantly the road vulnerability.

The procedure outlined in this paper proposes a methodology aimed to identify and quantify the economic vulnerability associated with a road transport infrastructure and, to evaluate the economic and social efficiency of a vulnerability reduction by the consideration of protective measures. Nevertheless, this procedure should be considered as a starting point and further improvements are strongly recommended. We suggest the extension of the economic loss with the estimation of the direct cost. It would be also interesting to enlarge the analysis to a wider geographical area in order to cover a better proportion of the potential infrastructure consumers. Finally, the integration of this module in a GIS environment would make the practitioner confident with the geographical context and the related hazards. 


\section{References}

Bell M.G.H., Iida Y., 1997. Transportation Network Analysis. Wiley, Chichester, West Sussex.

Bell M.G.H., Iida Y., 2003. The Network Reliability of Transport: Proceedings of the 1st International Symposium on Transportation Network Reliability (INSTR), Pergamon, Oxford.

Berdica, K., 2002. An introduction to road vulnerability: what has been done, is done and should be done. Transport Policy 9, 117-127.

Bolis, S., Maggi R., 2003. Logistics Strategy and Transport Service Choices-An Adaptive Stated Preference Experiment. In: Growth and Change - A journal of Urban and Regional Policy, Special Issue STELLA FG 1, (34) 4.

Chen, A., Yang, H., Lo, H.K., Tang, W.H., 2002. Capacity reliability of a road network: an assessment methodology and numerical results. Transportation Research Part B 36(3), 225-252.

Danielis, R., Marcucci, E., Rotaris, L., 2005. Logistics managers' stated preferences for freight service attributes. Transportation Research Part E 41(3), 201-215.

D'Este, G M and Taylor, M A P (2003). Network vulnerability: an approach to reliability analysis at the level of national strategic transport networks. In: Bell M.G.H., Iida Y. (Eds.), The Network Reliability of Transport: Proceedings of the 1st International Symposium on Transportation Network Reliability (INSTR). Pergamon, Oxford.

Fowkes, A.S., Firmin, P.E., Tweddle, G., Whiteing, A.E., 2004. How Highly Does the Freight Transport Industry Value Journey Time Reliability - and for What Reasons? International Journal of Logistics: Research and Applications 7, 33-44.

Hensher, D.A., Button, K.J., 2000. Handbook of transport modelling. Emerald Group Publishing.

Hensher, D.A., Greene, W.H., 2003. Mixed logit models: state of practice. Transportation 30(2), 133176.

Husdal, J., 2004. Reliability/vulnerability versus cost/benefit. In: Nicholson A.J., Dante, A., (Eds.), Proceedings of the Second International Symposium on Transportation Network Reliability (INSTR). Department of Civil Engineering, University of Canterbury, Christchurch, New Zealand.

Maggi, R., Rudel, R., 2008. The Value of Quality Attributes in Freight Transport: Evidence from an SP-Experiment in Switzerland. In: Ben-Akiva, M.E., Meersman, H., van de Voorde E. (Eds.), Recent Developments in Transport Modelling. Emerald Group Publishing Limited.

McFadden, D., 1974. Conditional logit analysis of qualitative choice behavior. In: Zarembka, P. (Ed.), Frontiers in Econometrics. Academic Press, New York.

Nicholson, A.J., Dante, A., 2004. Proceedings of the Second International Symposium on Transportation Network Reliability (INSTR). Department of Civil Engineering, University of Canterbury, Christchurch, New Zealand.

Taylor, M.A.P., D'Este, G.M., 2004. Critical infrastructure and transport network vulnerability: developing a method for diagnosis and assessment. In: Nicholson, A.J., Dante, A. (Eds.), Proceedings of the Second International Symposium on Transportation Network Reliability (INSTR). Department of Civil Engineering, University of Canterbury, Christchurch, New Zealand. 
Taylor, M.A.P., Sekhar, S.V.C., D’Este, G.M., 2006. Application of Accessibility Based Methods for Vulnerability Analysis of Strategic Road Networks. Networks and Spatial Economics 6, 267-291.

Train, K., 2003. Discrete Choice Methods with Simulation. Cambridge University Press, Cambridge.

Zamparini, L., Reggiani A., 2007. Freight Transport and the Value of Travel Time Savings: A Metaanalysis of Empirical Studies. Transport Reviews, 27(5), 621-636.

\section{Appendix}

Table A1. Critical points along the Ticino highway (A2) segment ${ }^{(*)}$.

\begin{tabular}{|c|c|c|c|c|}
\hline Location & Hazard & $\begin{array}{l}\text { Return } \\
\text { period } \\
\text { [years] }\end{array}$ & Type of protection & $\begin{array}{c}\text { Cost } \\
{[\mathrm{CHF}]}\end{array}$ \\
\hline Giornico & flooding & 100 & Paving ditch and retaining chamber reinforcement & $2^{\prime} 000^{\prime} 000$ \\
\hline Giornico & rockfall & 100 & Rockfall barriers & $1^{\prime} 0000^{\prime} 000$ \\
\hline Bellinzona & landslide & 100 & Retaining wall & $5000^{\prime} 000$ \\
\hline Capolago & flooding & 25 & $\begin{array}{l}\text { Retaining chamber and related frames reinforcement } \\
\text { (check dams, ditches, etc.) }\end{array}$ & $2^{\prime} 500^{\prime} 000$ \\
\hline $\begin{array}{l}\text { Collina d'Oro } \\
\text { (Gentilino) }\end{array}$ & landslide & 100 & Retaining wall & $5000^{\prime} 000$ \\
\hline $\begin{array}{l}\text { Faido } \\
\text { (Chioggiona) }\end{array}$ & rockfall & 100 & Wall coupled by rock fall ring nets & $2^{\prime} 5000^{\prime} 000$ \\
\hline $\begin{array}{l}\text { Faido } \\
\text { (Chioggiona) }\end{array}$ & rockfall & 100 & Rockfall barriers & $1^{\prime} 0000^{\prime} 000$ \\
\hline Quinto & avalanche & 100 & $\begin{array}{l}\text { Active measures (avalanche prevention structures as } \\
\text { snow barriers, snow racks and wire rope structures) } \\
\text { and passive measures (retention or control dams) }\end{array}$ & $3^{\prime} 0000^{\prime} 000$ \\
\hline
\end{tabular}

\footnotetext{
${ }^{(*)}$ We thank Mirko Baruffini for providing whit the information.
} 


\section{QUADERNI DELLA FACOLTÀ}

1998:

P. Balestra, Efficient (and parsimonious) estimation of structural dynamic error component models

1999:

M. Filippini, Cost and scale efficiency in the nursing home sector : evidence from Switzerland

L. Bernardi, I sistemi tributari di oggi : da dove vengono e dove vanno

L.L. Pasinetti, Economic theory and technical progress

G. Barone-Adesi, K. Giannopoulos, L. Vosper, VaR without correlations for portfolios of derivative securities

G. Barone-Adesi, Y. Kim, Incomplete information and the closed-end fund discount

G. Barone-Adesi, W. Allegretto, E. Dinenis, G. Sorwar, Valuation of derivatives based on CKLS interest rate models

M. Filippini, R. Maggi, J. Mägerle, Skalenerträge und optimale Betriebsgrösse bei den schweizerische Privatbahnen

E. Ronchetti, F. Trojani, Robust inference with GMM estimators

G.P. Torricelli, I cambiamenti strutturali dello sviluppo urbano e regionale in Svizzera e

nel Ticino sulla base dei dati dei censimenti federali delle aziende 1985, 1991 e 1995

2000:

E. Barone, G. Barone-Adesi, R. Masera, Requisiti patrimoniali, adeguatezza del capitale e gestione del rischio

G. Barone-Adesi, Does volatility pay?

G. Barone-Adesi, Y. Kim, Incomplete information and the closed-end fund discount

$\mathrm{R}$. Ineichen, Dadi, astragali e gli inizi del calcolo delle probabilità

W. Allegretto, G. Barone-Adesi, E. Dinenis, Y. Lin, G. Sorwar, A new approach to check the free boundary of single factor interest rate put option

G.D.Marangoni, The Leontief Model and Economic Theory

B. Antonioli, R, Fazioli, M. Filippini, // servizio di igiene urbana italiano tra concorrenza e monopolio

L. Crivelli, M. Filippini, D. Lunati. Dimensione ottima degli ospedali in uno Stato federale

L. Buchli, M. Filippini, Estimating the benefits of low flow alleviation in rivers: the case of the Ticino River

L. Bernardi, Fiscalità pubblica centralizzata e federale: aspetti generali e il caso italiano attuale

M. Alderighi, R. Maggi, Adoption and use of new information technology

F. Rossera, The use of log-linear models in transport economics: the problem of

commuters' choice of mode

2001:

M. Filippini, P. Prioni, The influence of ownership on the cost of bus service provision in

Switzerland. An empirical illustration

B. Antonioli, M. Filippini, Optimal size in the waste collection sector

B. Schmitt, La double charge du service de la dette extérieure

L. Crivelli, M. Filippini, D. Lunati, Regulation, ownership and efficiency in the Swiss

nursing home industry

S. Banfi, L. Buchli, M. Filippini, Il valore ricreativo del fiume Ticino per i pescatori

L. Crivelli, M. Filippini, D. Lunati, Effizienz der Pflegeheime in der Schweiz 
2002:

B. Antonioli, M. Filippini, The use of a variable cost function in the regulation of the Italian water industry

B. Antonioli, S. Banfi, M. Filippini, La deregolamentazione del mercato elettrico svizzero e implicazioni a breve termine per l'industria idroelettrica

M. Filippini, J. Wild, M. Kuenzle, Using stochastic frontier analysis for the access price regulation of electricity networks

G. Cassese, On the structure of finitely additive martingales

2003:

M. Filippini, M. Kuenzle, Analisi dell'efficienza di costo delle compagnie di bus italiane e svizzere

C. Cambini, M. Filippini, Competitive tendering and optimal size in the regional bus transportation industry

L. Crivelli, M. Filippini, Federalismo e sistema sanitario svizzero

L. Crivelli, M. Filippini, I. Mosca, Federalismo e spesa sanitaria regionale : analisi empirica per i Cantoni svizzeri

M. Farsi, M. Filippini, Regulation and measuring cost efficiency with panel data models : application to electricity distribution utilities

M. Farsi, M. Filippini, An empirical analysis of cost efficiency in non-profit and public nursing homes

F. Rossera, La distribuzione dei redditi e la loro imposizione fiscale : analisi dei dati fiscali svizzeri

L. Crivelli, G. Domenighetti, M. Filippini, Federalism versus social citizenship :

investigating the preference for equity in health care

M. Farsi, Changes in hospital quality after conversion in ownership status

G. Cozzi, O. Tarola, Mergers, innovations, and inequality

M. Farsi, M. Filippini, M. Kuenzle, Unobserved heterogeneity in stochastic cost frontier models : a comparative analysis

2004:

G. Cassese, An extension of conditional expectation to finitely additive measures

$\mathrm{S}$. Demichelis, O. Tarola, The plant size problem and monopoly pricing

F. Rossera, Struttura dei salari 2000 : valutazioni in base all'inchiesta dell'Ufficio federale di statistica in Ticino

M. Filippini, M. Zola, Economies of scale and cost efficiency in the postal services : empirical evidence from Switzerland

F. Degeorge, F. Derrien, K.L. Womack, Quid pro quo in IPOs : why book-building is dominating auctions

M. Farsi, M. Filippini, W. Greene, Efficiency measurement in network industries : application to the Swiss railway companies

L. Crivelli, M. Filippini, I. Mosca, Federalism and regional health care expenditures : an empirical analysis for the Swiss cantons

S. Alberton, O. Gonzalez, Monitoring a trans-border labour market in view of liberalization : the case of Ticino

M. Filippini, G. Masiero, K. Moschetti, Regional differences in outpatient antibiotic consumption in Switzerland

A.S. Bergantino, S. Bolis, An adaptive conjoint analysis of freight service alternatives :

evaluating the maritime option

2005:

M. Farsi, M. Filippini, An analysis of efficiency and productivity in Swiss hospitals

M. Filippini, G. Masiero, K. Moschetti, Socioeconomic determinants of regional

differences in outpatient antibiotic consumption : evidence from Switzerland 
2006:

M. Farsi, L. Gitto, A statistical analysis of pain relief surgical operations

M. Farsi, G. Ridder, Estimating the out-of-hospital mortality rate using patient discharge data

S. Banfi, M. Farsi, M. Filippini, An empirical analysis of child care demand in Switzerland

L. Crivelli, M. Filippini, Regional public health care spending in Switzerland : an empirical analysis

M. Filippini, B. Lepori, Cost structure, economies of capacity utilization and scope in Swiss higher education institutions

M. Farsi, M. Filippini, Effects of ownership, subsidization and teaching activities on hospital costs in Switzerland

M. Filippini, G. Masiero, K. Moschetti, Small area variations and welfare loss in the use of antibiotics in the community

A. Tchipev, Intermediate products, specialization and the dynamics of wage inequality in the US

A. Tchipev, Technological change and outsourcing : competing or complementary explanations for the rising demand for skills during the 1980s?

2007:

M. Filippini, G. Masiero, K. Moschetti, Characteristics of demand for antibiotics in primary care : an almost ideal demand system approach

G. Masiero, M. Filippini, M. Ferech, H. Goossens, Determinants of outpatient antibiotic consumption in Europe : bacterial resistance and drug prescribers

R. Levaggi, F. Menoncin, Fiscal federalism, patient mobility and the soft budget constraint : a theoretical approach

M. Farsi, The temporal variation of cost-efficiency in Switzerland's hospitals : an application of mixed models

2008:

Quaderno n. 08-01

M. Farsi, M. Filippini, D. Lunati, Economies of scale and efficiency measurement in

Switzerland's nursing homes

Quaderno n. 08-02

A. Vaona, Inflation persistence, structural breaks and omitted variables : a critical view Quaderno n. 08-03

A. Vaona, The sensitivity of non parametric misspecification tests to disturbance autocorrelation

Quaderno n. 08-04

A. Vaona, STATA tip : a quick trick to perform a Roy-Zellner test for poolability in STATA Quaderno n. 08-05

A. Vaona, R. Patuelli, New empirical evidence on local financial development and growth Quaderno n. 08-06

C. Grimpe, R. Patuelli, Knowledge production in nanomaterials : an application of spatial filtering to regional system of innovation

Quaderno n. 08-07

A. Vaona, G. Ascari, Regional inflation persistence : evidence from Italy Quaderno n. 08-08

M. Filippini, G. Masiero, K. Moschetti, Dispensing practices and antibiotic use Quaderno n. 08-09

T. Crossley, M. Jametti, Pension benefit insurance and pension plan portfolio choice 
Quaderno n. 08-10

R. Patuelli, A. Vaona, C. Grimpe, Poolability and aggregation problems of regional innovation data : an application to nanomaterial patenting

Quaderno n. 08-11

J.H.L. Oud, H. Folmer, R. Patuelli, P. Nijkamp, A spatial-dependence continuous-time model for regional unemployment in Germany

2009:

Quaderno n. 09-01

J.G. Brida, S. Lionetti, W.A. Risso, Long run economic growth and tourism : inferring from Uruguay

Quaderno n. 09-02

R. Patuelli, D.A. Griffith, M. Tiefelsdorf, P. Nijkamp, Spatial filtering and eigenvector stability : space-time models for German unemployment data

Quaderno n. 09-03

R. Patuelli, A. Reggiani, P. Nijkamp, N. Schanne, Neural networks for cross-sectional employment forecasts : a comparison of model specifications for Germany

Quaderno n. 09-04

A. Cullmann, M. Farsi, M. Filippini, Unobserved heterogeneity and International benchmarking in public transport

Quaderno n. 09-05

M. Jametti, T. von Ungern-Sternberg, Hurricane insurance in Florida

Quaderno n. 09-06

S. Banfi, M. Filippini, Resource rent taxation and benchmarking : a new perspective for the Swiss hydropower sector

Quaderno n. 09-07

S. Lionetti, R. Patuelli, Trading cultural goods in the era of digital piracy

Quaderno n. 09-08

M. Filippini, G. Masiero, K. Moschetti, Physician dispensing and antibiotic prescriptions

2010:

Quaderno n. 10-01

R. Patuelli, N. Schanne, D.A. Griffith, P. Nijkamp, Persistent disparities in regional unemployment : application of a spatial filtering approach to local labour markets in Germany

Quaderno n. 10-02

K. Deb, M. Filippini, Public bus transport demand elasticities in India

Quaderno n. 10-03

L. Masiero, R. Maggi, Estimation of indirect cost and evaluation of protective measures for infrastructure vulnerability : a case study on the transalpine tran sport corridor 